\title{
Successful Surgical Treatment of a Giant Left Ventricular Aneurysm
}

\author{
COSMIN BANCEU1', MARIUS HARPA ${ }^{1 *}$, KLARA BRINZANIUC ${ }^{2}$, JUDIT KOVACS ${ }^{3}$, MIHAELA MALOS ${ }^{4}$, HUSSAM AL HUSSEIN ${ }^{1}$, \\ MARIUS CIORBA ${ }^{5}$, HORATIU SUCIU ${ }^{1}$ \\ ${ }^{1}$ Emergency Institute for Cardiovascular Diseases and Transplant Tirgu Mures, Departement of Cardiac Surgery, 50 Gheorghe \\ Marinescu Str., 540136, Tirgu Mures, Romania \\ 2University of Medicine and Pharmacy of Tirgu Mures, Department of Anatomy and Embryology, 38 Gheorghe Marinescu Str., \\ 540139, Tirgu Mures, Romania \\ ${ }^{3}$ University of Medicine and Pharmacy of Tirgu Mures, Department of Cardiac Anesthesiology, 50 Gheorghe Marinescu Str., \\ 540136, Tirgu Mures, Romania \\ ${ }^{4}$ Emergency Institute for Cardiovascular Diseases and Transplant Tirgu Mures, Departement of Cardiology, 50 Gheorghe Marinescu \\ Str., 540136, Tirgu Mures, Romania \\ ${ }^{5}$ Emergency Clinical County Hospital Tîrgu Mures, Department of Gastroenterology, 50 Gheorghe Marinescu Str., 540136, Tirgu \\ Mures, Romania
}

\begin{abstract}
Left ventricular anevrysm (LVA) is the effect of left ventricular (LV) remodeling after myocardial infarction (MI). The surgical technique to improve cardiac function is geometric reconstruction of the LV. The aim of this paper is to highlight the importance of restoring left ventricle geometry. We report a case of 53 year-old man, without any known cardiovascular history, with acute anterior myocardial infarction, left ventricular aneurysm and massive left ventricular thrombus, who arrived into the emergency department 24 hours after the onset of symptomatology. After hemodynamic stabilization, we performed geometric reconstruction of the left ventricle. With favorable postoperative evolution, patient is discharged 14 days later. At the periodic checkups it is noted that he's postoperative ejection fraction (EF) improved and also the quality of life.
\end{abstract}

\section{Keywords: DOR procedure, left ventricular anevriysm, thrombus}

Left ventricular aneurysm (LVA) is a consequence of transmural myocardial infarction, resulting from left anterior descending artery (LAD) occlusion, this vessel vascularizing the anterior side of the left ventricle and the anterior portion of interventricular septum.[1] Another possibility of developing left ventricular aneurysm is when the vascularization of the heart is right dominant type and transmural myocardial infarction occurs by occlusion of the right coronary artery and the patient presents associated, at the same time, circumflex artery (LCX) significant stenosis[2].

It is assumed that the lack of coronary collaterals causes the appearance of the left ventricular aneurysm in the case of anterior descending artery occlusion[3,4].

Approximately $80 \%$ of left ventricular aneurysm is located antero-laterally near the apex of heart [5].

The incidence of left ventricular aneurysm is $10-30 \%$ in patients suffering from a myocardial infarction [4] the incidence exhibiting a downward trend due to thrombolysis and myocardial percutaneous revascularization performed in the first few hours of onset of myocardial infarction [2].

There is a death rate of $69 \%$ in the first 5 years for patients who present myocardial akinesia zones in the context of left ventricular aneurysm and no surgical intervention [4].

Left ventricular aneurysm and myocardial infarction scar predispose the heart to ventricular arrhythmias [6], this being a surgical indication [7].

As a compensatory response of myocardial remaining tissue, the left ventricle passes through a remodeling cardiac process that will cause left ventricular dilatation and EF decrease [8] with congestive heart failure and increased incidence of ventricular arrhythmias followed by death [7].

In case of intracavitary thrombus, it presents 19\% systemic or cerebral embolism risk in the first 24 months if the patient does not undergo surgery [2].
DOR procedure, known as endoventricular circular patch plasty repair, is a surgical procedure that isolates segmentally ineffective myocardium from the rest of the myocardium, using the circular patch to reconstruct as faithfully as possible the ventricular cavity. $[5,9]$ Ventriculotomy is performed in parallel to the LAD traject at 2-3 cm laterally, so that cardiorrhaphy can be safety performed without scarifying the LAD.[3]

The aim of this paper is to highlight the importance of restoring left ventricle geometry.

Signed informed consent was obtained for publication of scientific data.

\section{Experimental part}

A 53 year-old patient, without any cardiovascular history, arrived to Emergency Departament, with epigastric pain, started $24 \mathrm{~h}$ before and lasting more than $30 \mathrm{~min}$, irradiating to the back level, dorsal and left upper limb, associated with cold transpiration, nausea and dyspnea, signs of congestive heart failure NYHA III/IV.

Clinical and paraclinical investigations reveal blood pressure $60 / 40 \mathrm{mmHg}$, heart rate 119 per min, CTnl 19.6 $\mathrm{ng} / \mathrm{mL}, \mathrm{CKMB} 467 \mathrm{ng} / \mathrm{mL}$, left segment elevation in V2-V6, DI-DIII, R amputated in V2-V6, DI, DII, aVL. Based on this, the case was interpreted as a previous STEMI myocardial infarction.

Late presentation of the patient to hospital made invasive strategy including percutaneous coronary intervention ineffective.

The echocardiographic examination showed left ventricular dysfunction with severe reduction in global contractility, EF 30\%, and mechanical dyssynchrony and also, apical LV, 1|3 apical lateral wall and interventricular septum akinesia, spontaneous eco- contrast in the left ventricle, mitral regurgitation $2+$, tricuspid regurgitation $2+, L V=53141 \mathrm{~mm}, \mathrm{LV}$ volume $=147 \mathrm{~mL}$, pericardial

\footnotetext{
*email; marius_harpa@yahoo.com, Phone: +40740311396
} 
effusion more than $20 \mathrm{~mm}$ without cardiac compression, LV apical thrombosis with subacute ventricular rupture.

The computed tomography angiography examination (fig. 1) revealed a LV aneurysm with voluminous apical thrombus $(5 / 4 \mathrm{~cm}, 5 / 3 \mathrm{~cm})$, and a thrombus recanalized at a $3.2 \mathrm{~cm}$ length at the level of the previous LAD (fig. 2).

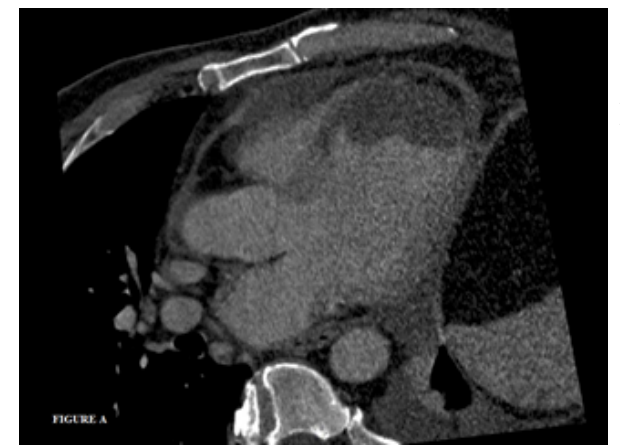

Fig. 1. Voluminous apical thrombus located in the left ventricule aneurysm

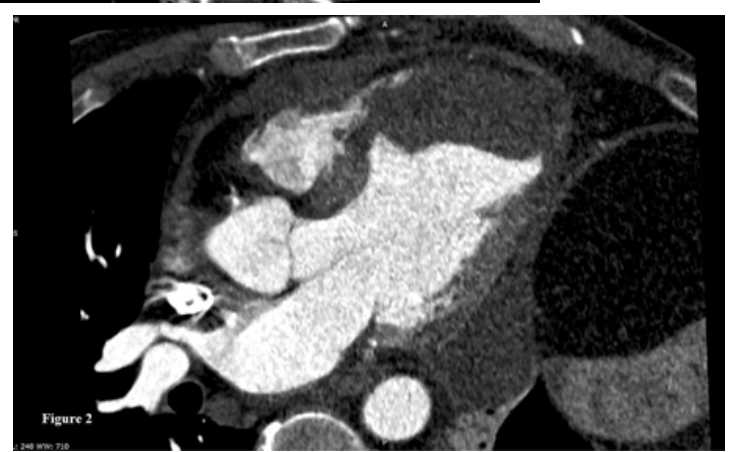

Fig. 2. Recanalized thrombus at the level of $L A D$

Due to the presence of the intracavitary thrombus and the major embolism risk, after hemodynamic stabilization of the patient with loop diuretic (Furosemide $80 \mathrm{mg} /$ day), inotropic support (Dopamine $250 / 50 \mathrm{~mL}-4 \mathrm{~mL} / \mathrm{h}$ ) surgery is decided to remove the thrombus and exclude the left ventricular aneurysm by geometric reconstruction.

Because of the anteroapical localization of the aneurysm, we considered that the best surgical strategy is DOR procedure, the technique of endoanevrysmorrhaphy.

Aneurysmectomy, debridement and intramural thrombus excision were performed (fig. 3).

Intraoperatively, the junctional boundary between the post-infarct scar tissue and indwelling myocardial muscle is identified, and the aneurysmal area with heterologous pericardium and Certex is excluded by continuous circular suture (fig. 4).

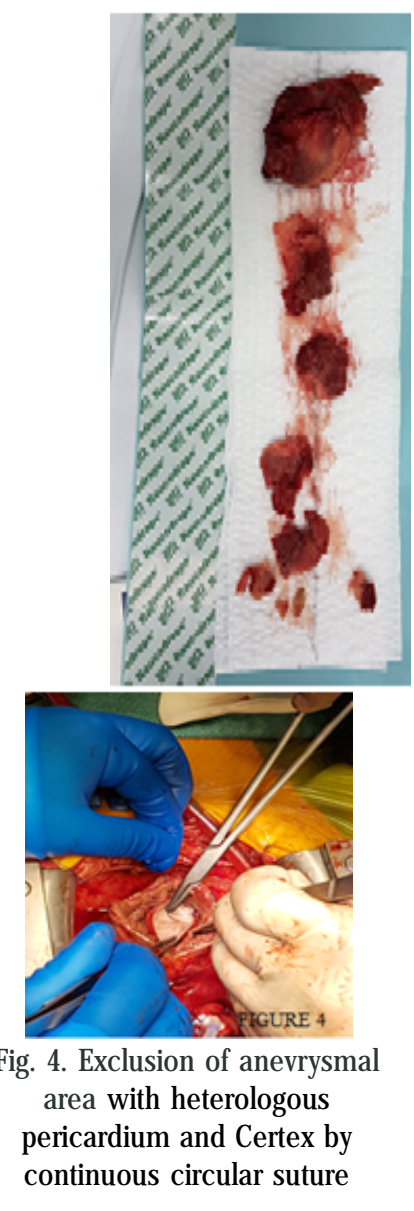

Fig. 3.Intramural thrombus excision intraoperatively

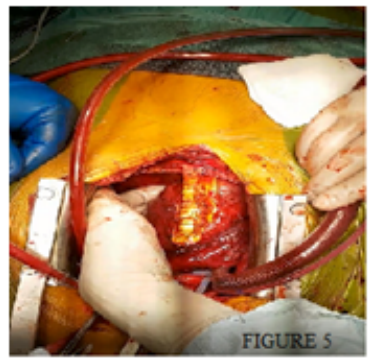

Fig. 5. Exclusion of anevrismal scar on PTFE pledgets and specific surgical glue

The aneurysmal scar is excluded by performing a reinforced 3.0 polypropylene on PTFE pledgets, minimizing the risk of bleeding by using specific surgical glue (fig. 5).

The echocardiographic postoperative assessment, showed an $\mathrm{EF}$ increase to $35 \%, \mathrm{LV}=40 \mathrm{~mm}$, LV volume = $128 \mathrm{ml}$ with akinesia of the apex interventricular septum and anterolateral wall of the LV, mitral regurgitation 1+, tricuspid regurgitation $2+$, without pericardial effusion.

The patient is discharged two weeks later, hemodynamically and respiratory stable, with platelet antiaggregation therapy, beta- blocker, IECA, in minimal doses.

Follow-up at 3, 69 , and 12 months revealed an $\mathrm{EF}=$ $40 \%$, LV volume $=138 \mathrm{ml}$, (fig. 6) no visible intracavitary thrombus, mitral regurgitation $1+$, without pericardial effusion, improved quality of life, without subjective complaints of rest or medium effort.

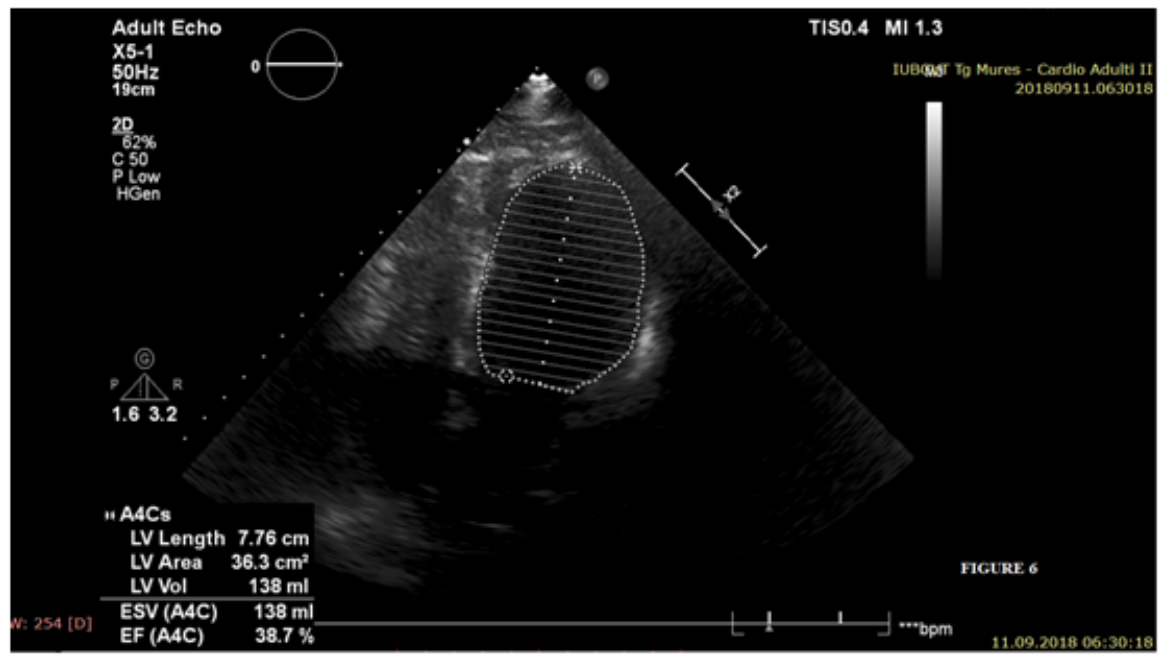

Fig. 6. 1 year follow-up echocardiographic with $\mathrm{EF} 40 \%$, LV volume $=138 \mathrm{~mL}$ 


\section{Results and discussions}

Left ventricular aneurysm is one of the complications of myocardial infarction, but due to early myocardial percutaneous revascularization, the incidence of left ventricular aneurysm has declined lately [2].

The main complications of these patients are strokes, systemic embolization, left ventricular rupture, ventricular arrhythmias, death [5] and this is the reason why surgery is a sine qua non.

The gold standard of this surgery is to exclude integral thrombogenic material, to reconstruct the left ventricle by geometric reconstruction of the ventricle, and to improve the ejection fraction [9].

\section{Conclusions}

Complete exclusion of the intraventricular thrombus is vital to minimizing the embolism risk.

Choosing the right operative technique is important to restore left ventricular function to optimal parameters.

Surgery is essential in reconstruction of the left ventricle, while removing possible complications (such as strokes, systemic embolization, left ventricular wall rupture, ventricular arrhythmias, death), significantly improves the quality of life, and long term survival is assured.

Acknowledgements: We thank to Dr. Pop Marian for his help with the imaging part.

\section{References}

1. RUZZA A, CZER L, ARABIA F, VESPIGNANI R, ESMAILIAN F, CHENG W, DE ROBERIS M, TRENTO A. Left Ventricular Reconstruction for Postinfarction Left Ventricular Anevrism: Review of Surgical Techiques. Tex Heart Inst J . 2017, 44(5), p 326-335.

2. LAURENCE H. Cohn. Cardiac Surgery in the Adult. $3^{\text {th }}$ ed. USA: The McGraw-Hill Companies, Inc, 2008, p. 803-821.

3. MUKADDIROV M, DEMARIA RG, PERRAULT LP, FRAPIER J M, ALBAT $B$. Reconstructive surgery of postinfarction left ventricular anevrysms: techniques and unsolved problems. Eur J Cardiothorac Surg, 2008, 34(2), p 256-261.

4. MILLS N, EVERSON C, HOCKMUTH D.Techincal Advances in the treatament of left ventricular anevrysm: Ann Thorac Surg, 1993, 55, p 792-800

5. COX JL. Surgical management of left ventricular aneurysm: a clarification of similarities and differences between the Jatene and Dor techniques. Semin Thorac Cardiovasc Surg, 1997, 9(2), p 131-138. 6. ARSENESCU GEORGESCU, C., ANGHEL, L., The Significance of New Left Bundle Branch Block Complicating Acute Myocardial Infarction, Rev. Chim., (Bucharest), 69, no. 1, 2018, p. 144

7. SCHAITZA G, NETO J, FRANCISCO J, BAENA C, GRIFFHORN H, OLANDOSKI B, DE MEIRA L, GUARITA- SOUZA L. Surgical treatment of a giant left ventricular anevrysm- A case report, Rev Bras Cir Cardiovasc, 2014, 29 (4), p. 663- 666.

8. STOODLEY P, RICHARDS D. Anatomical and physiological complication related to left ventricular apical anevrysm, Australasian Sonographers Association, 2016, 4, p.70-75.

9. YAN J, JIANG S. Impact of surgical ventricular restoration on early and long- term outcomes of patients with left ventricular anevrysm $A$ single-center experience, Yan and Jiang Medicine, 2018, 97, p. 41.

Manuscript received: 24.01 .2019 